\title{
Short and long-term behaviour of RC slabs strengthened with prestressed CFRP laminate strips
}

\begin{tabular}{|r|l|}
\hline Journal: & IABSE/Vancouver 2017 \\
\hline Manuscript ID & YVR-0697-2017.R2 \\
\hline Theme: & Existing Structures into the Future \\
\hline Date Submitted by the Author: & n/a \\
\hline Complete List of Authors: & $\begin{array}{l}\text { Sena-Cruz, José; Universidade do Minho - Campus de Azurem, Civil } \\
\text { Engineering } \\
\text { Correia, Luís; Universidade do Minho - Campus de Azurem } \\
\text { França, Paulo; Universidade da Madeira } \\
\text { Michels, Julien; Empa Materials Science and Technology }\end{array}$ \\
\hline Material and Equipment: & Concrete, Composites, Prestressing \\
\hline Type of Structure: & Bridges, Buildings \\
\hline Other Aspects: & Durability, Rehabilitation, Testing \\
\hline & \multicolumn{2}{|l}{} \\
\hline
\end{tabular}




\title{
Short and long-term behaviour of RC slabs strengthened with prestressed CFRP laminate strips
}

\author{
José Sena-Cruz, Luís Correia \\ ISISE, University of Minho, Guimarães, Portugal \\ Paulo França \\ CEris, ICIST and CCCEE, University of Madeira, Funchal, Portugal \\ J. Michels \\ re-fer AG, Brunnen, Switzerland / Empa, Dübendorf, Switzerland \\ Contact: isena@civil.uminho.pt
}

\begin{abstract}
In the context of strengthening reinforced concrete $(\mathrm{RC})$ structures with fiber reinforced polymer (FRP) materials, the externally bonded reinforcement (EBR) technique is the most widely used strategy. By prestressing the FRP materials attached to the concrete substrate, the advantages of external prestressing and of the EBR technique are combined. The solutions adopting carbon FRP (CFRP) laminates have been mostly used.

Special end-anchorage systems are required at the ends of the prestressed CFRP laminate to transfer the high shear stresses developed from the FRP to concrete, in order to avoid a premature FRP peeling-off failure. From all the proposed systems, two of them have been prevailed, mainly: the mechanical anchorage (MA) fixed to the ends of the FRP reinforcement and the gradient anchorage (GA).

The present work investigates the short and long-term behaviour, including the durability issues, of reinforced concrete (RC) slabs strengthened with prestressed CFRP strips according the EBR technique. Two different anchorage systems were studied: (i) MA and (ii) GA. The experimental program carried out included of the effects of environmental actions such as water, water with chlorides and wet-dry cycles on the global performance of these slabs. This paper presents the general description of the experimental program, the analysis of the main results, as well as the retained conclusions.
\end{abstract}

Keywords: EBR; CFRP; prestress; Anchorage; durability; long-term behaviour; RC structures 


\title{
Short and long-term behaviour of RC slabs strengthened with prestressed CFRP laminate strips
}

\author{
José Sena-Cruz, Luís Correia \\ ISISE, University of Minho, Guimarães, Portugal \\ Paulo França \\ CEris, ICIST and CCCEE, University of Madeira, Funchal, Portugal \\ J. Michels \\ re-fer AG, Brunnen, Switzerland / Empa, Dübendorf, Switzerland \\ Contact: jsena@civil.uminho.pt
}

\begin{abstract}
In the context of strengthening reinforced concrete $(R C)$ structures with fibre reinforced polymer (FRP) materials, the externally bonded reinforcement (EBR) technique is the most widely used strategy. By prestressing the FRP materials attached to the concrete substrate, the advantages of external prestressing and of the EBR technique are combined. The solutions adopting carbon FRP (CFRP) laminates have been mostly used.

Special end-anchorage systems are required at the ends of the prestressed CFRP laminate to transfer the high shear stresses developed from the FRP to concrete, in order to avoid a premature FRP peeling-off failure. From all the proposed systems, two of them have been prevailed, mainly: the mechanical anchorage (MA) fixed to the ends of the FRP reinforcement and the gradient anchorage (GA).

The present work investigates the short and long-term behaviour, including the durability issues, of reinforced concrete (RC) slabs strengthened with prestressed CFRP strips according the EBR technique. Two different anchorage systems were studied: (i) MA and (ii) GA. The experimental program carried out included of the effects of environmental actions such as water, water with chlorides and wet-dry cycles on the global performance of these slabs. This paper presents the general description of the experimental program, the analysis of the main results, as well as the retained conclusions.
\end{abstract}

Keywords: EBR; CFRP; prestress; Anchorage; durability; long-term behaviour; RC structures 


\section{Introduction}

The externally bonded reinforcement (EBR) technique is the most common practice in improving existing reinforced concrete (RC) structures with carbon FRP (CFRP) materials. EBR with prestressed fibre reinforced polymer (FRP) materials combines the benefits of the EBR technique with the ones provided by the external prestressing. Literature [1-2] reports several benefits when the combination of these two techniques is used.

The success of the prestressing technique directly depends on the type of end anchorage. Among all the proposed systems, two are particularly relevant: (i) the mechanical anchorage (MA) system, which fixes the ends of the FRP reinforcement to the concrete substrate by means of metallic plates and bolts, and (ii) the gradient anchorage (GA) that uses the adhesive's ability to cure faster at high temperatures to create a nonmechanical anchorage. Up to now, the majority of the research works focused on the study of new prestressing systems as well as on the structural behaviour in terms of serviceability and ultimate resistance of the strengthened elements at a short-term.

In this context, the present work aims at contributing for a better understating the durability related aspects of RC slabs strengthened with prestressed EBR CFRP laminates. In this sense, an experimental program was carried out where the type anchorage system, the environmental condition and the loading scheme were the main variables studied. After being subjected to the specified environmental conditions and to the prescribed loading scheme for a period of eight months, the slabs were monotonically tested up to failure, under displacement control and using a four-point bending test configuration. The influence of both the environmental conditions, and the cracking developed due to the sustained load on the overall performance of the prestressing systems are also discussed in the present work. Finally, the short and long-term losses of the CFRP strain, as well as the time-dependent behaviour (creep behaviour) are presented and discussed.

\section{Experimental Investigation}

\subsection{Experimental program, specimens and test configuration}

The experimental program was composed of 12 slabs (see Table 2): (i) one control specimen (REF_TO); (ii) one specimen strengthened with one CFRP laminate strip according to the EBR technique (EBR_TO); and (iii) ten specimens strengthened with one prestressed CFRP laminate strip, five by using the mechanical anchorage (MA) system and five with the gradient anchorage (GA) system. As it is shown in Table 2 all specimens are labelled with a generic denomination: $X \_Y$, where $X$ indicates the type of anchorage (MA or GA), $Y$ stands for the environmental action (TO, REF, TW, CW and WD).

The geometry and test configuration adopted to assess the time-dependent (creep) behaviour and durability are presented in Figure 1. All slabs are $2600 \mathrm{~mm}$ long, $600 \mathrm{~mm}$ wide and $120 \mathrm{~mm}$ thick. Each slab was designed with five steel bars with a diameter of $8 \mathrm{~mm}(5 \phi 8)$ as bottom reinforcement and with three steel bars with a diameter of $6 \mathrm{~mm}$ (3ф6) as top reinforcement. The concrete cover was $20 \mathrm{~mm}$. Stirrups of $\phi 6$ at $300 \mathrm{~mm}$ spacing were adopted as transverse reinforcement. With the exception of slab REF_TO, all slabs were strengthened with a $2200 \mathrm{~mm}$ long CFRP laminate strip, with a cross section of $50 \times 1.2 \mathrm{~mm}^{2}$.

The instrumentation in the quasi-static monotonic tests up to the failure (see Figure 1a) included 5 LVDTs to measure the vertical displacement along the longitudinal axis, four strain gauges TML BFLA5-3 to record the CFRP strains and one load cell to register the applied force (F). Tests were performed using a servo controlled equipment under displacement control at a rate of $1.2 \mathrm{~mm} / \mathrm{min}$. The creep tests follow also a 4-point bending test configuration. The instrumentation used in the creep tests (see Figure 1b) included one LVDT and one optical fibre strain sensor at the mid-span. The optical fibre sensors (HBM FiberSensing ${ }^{\circledR}$ FS6200) are Fibber Bragg Grating (FBG) based sensors with a gauge length of 92 $\mathrm{mm}$, measuring range of $\pm 2500 \mu \varepsilon$ and a resolution equal to $1 \mu \varepsilon$. 
a

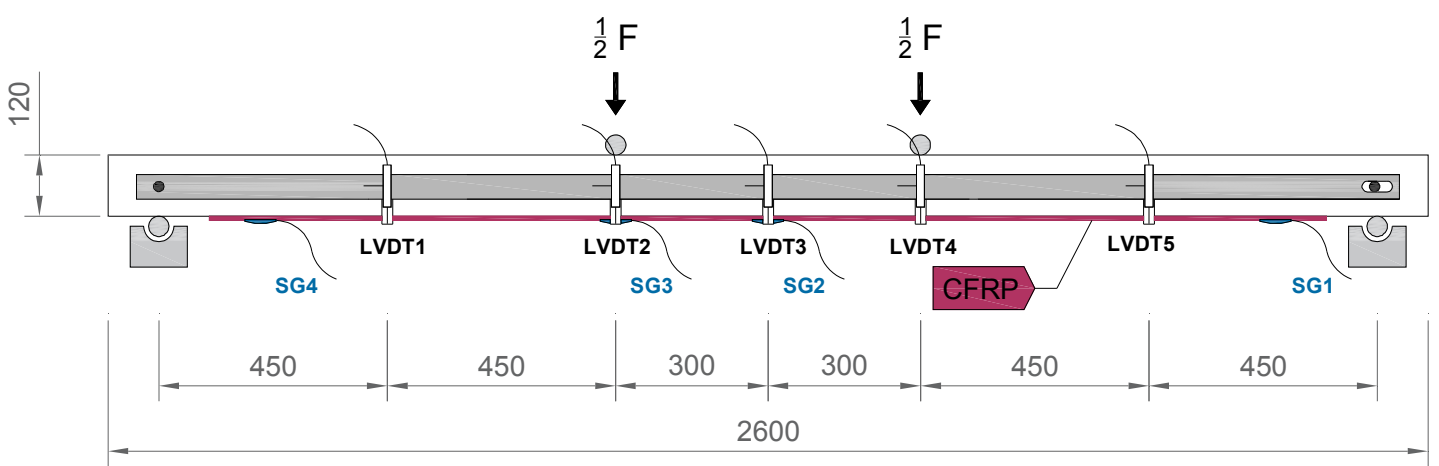

b
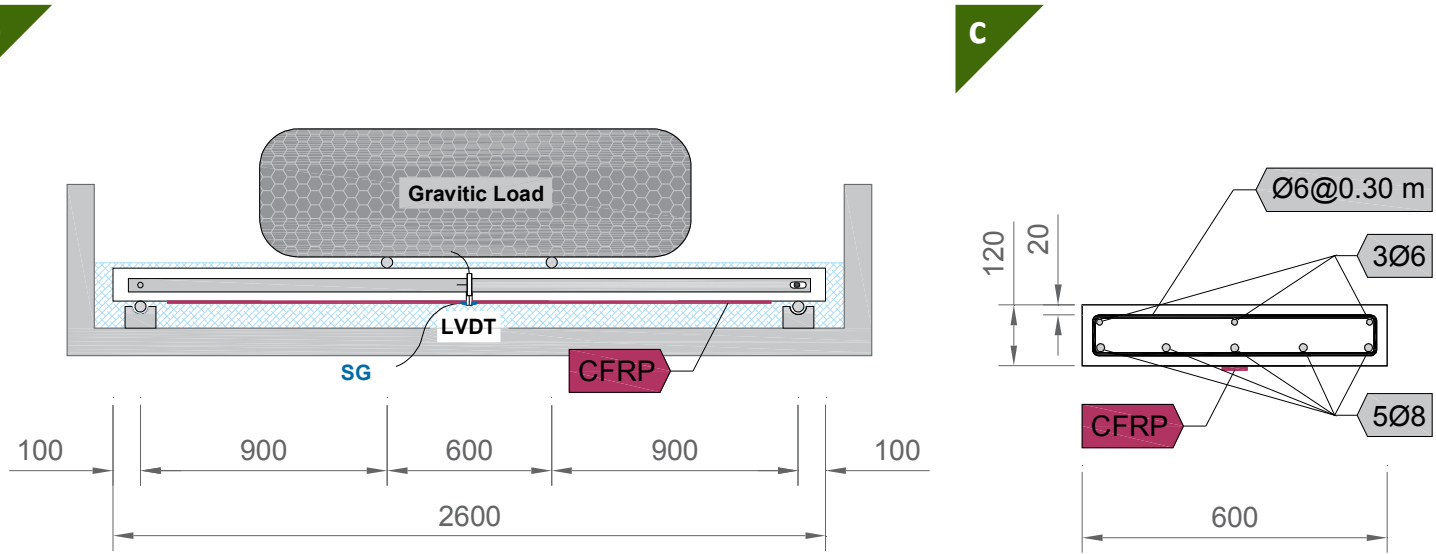

Figure 1. Specimens geometry and tests configuration: a) monotonic test configuration; b) creep test configuration; and c) cross-section. Note: all units in [mm]

\subsection{Materials}

Material characterization included the evaluation of the mechanical properties of the materials involved in this experimental program, namely, concrete, steel, CFRP laminate and epoxy adhesive.

A concrete grade $\mathrm{C} 30 / 37$ with a maximum aggregate size of $12.5 \mathrm{~mm}$ was used. Six cylindrical concrete specimens with $150 \mathrm{~mm}$ of diameter and $300 \mathrm{~mm}$ of high were used to evaluate the modulus of elasticity and compressive strength through the LNEC E397-1993:1993 and NP EN 12390-3:2011 recommendations, respectively. These tests were performed at the same age of the slabs monotonic tests and the results are presented in Table 1. From these results, the modulus of elasticity $\left(E_{c}\right)$ and the ultimate strength $\left(f_{c}\right)$ increased for the specimens immersed in water (series TW, CW and WD). Particularly, for the series TW, the Young's modulus increased $11.3 \%$ and the compressive strength $24.9 \%$, when compared with the reference series (TO).

The tensile properties of the steel reinforcement were evaluated with the NP EN ISO 6892-1:2012 standard. Four steel bar samples with $500 \mathrm{~mm}$ were used in the characterization of each bar type. The mean values for the modulus of elasticity $\left(E_{s}\right)$, as well as yield $\left(f_{y}\right)$ and ultimate $\left(f_{u}\right)$ tensile strengths are presented in Table 1.

The CFRP laminate strips (Type: S\&P Laminate CFK) consist of unidirectional carbon fibres held together by an epoxy vinylester resin. In order to assess its tensile properties, six samples of CFRP 
laminate were tested in accordance with the ISO 527-5:1997 recommendations. Results are also presented in Table 1.

In the present experimental campaign, the epoxy adhesive (Type: S\&P Resin 220) was not characterized. However, in another experimental program made by the authors, after 7 days of curing at $21{ }^{\circ} \mathrm{C}$ a modulus elasticity of $8.7 \mathrm{GPa}$ $(\mathrm{CoV}=6.0 \%)$ and a tensile strength of $20.7 \mathrm{MPa}$ (CoV=11.0\%) were obtained [3].

Table 1. Material characterization

\begin{tabular}{ccc} 
CONCRETE & & \\
\hline SERIES & $\begin{array}{c}\mathbf{E}_{\mathbf{c}} \\
{[\mathrm{GPa}]}\end{array}$ & $\begin{array}{c}\mathbf{f}_{\mathrm{c}} \\
{[\mathrm{MPa}]}\end{array}$ \\
\hline TO & $30.0(-)$ & $40.2(0.7 \%)$ \\
\hline REF & $26.9(2.4 \%)$ & $39.5(5.3 \%)$ \\
\hline TW & $33.4(1.3 \%)$ & $50.2(1.3 \%)$ \\
\hline CW & $33.8(1.1 \%)$ & $45.9(8.0 \%)$ \\
\hline WD & $32.2(5.1 \%)$ & $48.6(2.1 \%)$ \\
\hline
\end{tabular}

STEEL

\begin{tabular}{cccc}
\hline BAR TYPE & $\begin{array}{c}\mathbf{E}_{\mathbf{c}} \\
{[\mathrm{GPa}]}\end{array}$ & $\begin{array}{c}\mathbf{f}_{\mathbf{c}} \\
{[\mathrm{MPa}]}\end{array}$ & $\begin{array}{c}\mathbf{F}_{\mathbf{u}} \\
{[\mathrm{MPa}]}\end{array}$ \\
\hline \multirow{2}{*}{$\phi 6$} & 206.9 & 519.4 & 670.2 \\
& $(0.4 \%)$ & $(6.1 \%)$ & $(5.1 \%)$ \\
\hline \multirow{2}{*}{$\Phi 8$} & 235.1 & 595.9 & 699.0 \\
& $(4.6 \%)$ & $(4.1 \%)$ & $(2.1 \%)$ \\
\hline
\end{tabular}

\begin{tabular}{lcc}
\hline CFRP & \\
\hline $\begin{array}{c}\text { GEOMETRY } \\
{\left[\mathrm{mm}^{2}\right]}\end{array}$ & $\begin{array}{c}\mathbf{E}_{\mathrm{f}} \\
{[\mathrm{GPa}]}\end{array}$ & $\begin{array}{c}\mathbf{f}_{\mathrm{f}} \\
{[\mathrm{MPa}]}\end{array}$ \\
\hline $50 \times 1.2$ & $167.7(2.9 \%)$ & $2943.5(1.6 \%)$ \\
\hline
\end{tabular}

Note: The values between parentheses are the corresponding coefficients of variation (CoV).

\subsection{Strengthening procedures}

Ten slabs were strengthened with a prestressed CFRP laminate strip using two different anchorage systems (MA and GA). The strengthening procedure included several steps. Initially the concrete surface was sandblasted in the region where the laminate was applied. Then, the typical procedures for the application of the MA [4] and the GA [2] methods were followed. A prestress level of $40 \mathrm{kN}$ (corresponding to a prestrain $\left(\varepsilon_{\mathrm{fp}}\right)$ of $0.4 \%$ ) was applied to the CFRP laminates.

All specimens were kept in the lab environment after strengthening at least one month before proceeding with the next steps. The T0 slabs were tested up to failure and the remaining slabs were placed into their corresponding environments, for a period of eight months: (i) laboratory premises with a controlled temperature of $20{ }^{\circ} \mathrm{C}$ and relative humidity of $55 \%$ (series REF); (ii) immersion in tap water at $20{ }^{\circ} \mathrm{C}$ (series TW); (iii) immersion in water at $20^{\circ} \mathrm{C}$ with $3.5 \%$ of chlorides (series CW); and, (iv) wetting-drying cycles with tap water at $20{ }^{\circ} \mathrm{C}$ and without chlorides (series WD). During the same period, the slabs were also subjected to a sustained loading of $20 \mathrm{kN}$ (approximately $1 / 3$ of its maximum capacity). Then, the sustained load was removed and all ten specimens were placed in the lab environment for a minimum period of one month. Finally, the specimens were tested up to failure. The timeframe of the developed work is illustrated in Figure 2.

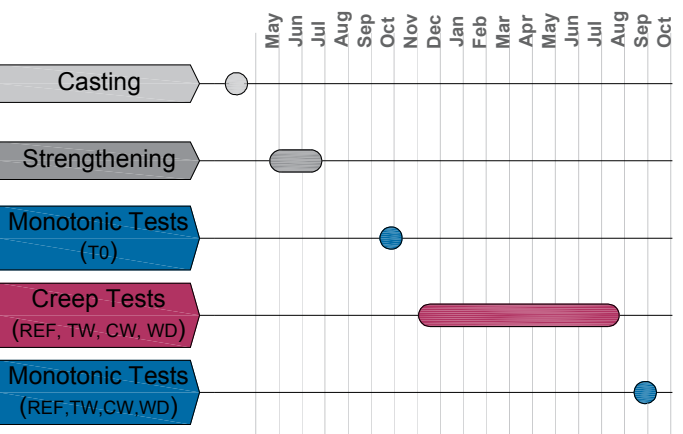

Figure 2. Timeframe of the developed work

It should be pointed out that the specimen GA_REF had to be disregarded due to a technical problem that occurred in the air-conditioning system of the climatic chamber. Consequently, corresponding information is not included in the present work. 


\section{Results and discussion}

\subsection{Short and long-term behaviour}

The prestress losses consists of instantaneous losses and time-dependent losses. Through a continuous monitoring of the CFRP strains, the instantaneous prestress losses were measured. Both anchorage systems exhibit minor initial losses. On the MA system, these losses $(\approx 1.4 \mathrm{kN})$ are observed when the prestress system is blocked, and the force is transferred from the hydraulic jack to the fixing screws. The GA system exhibits smaller losses $(\approx 0.8 \mathrm{kN})$ which were only detected at the first release of prestressing force (1/3 of the total pre-stressing force). Table 2 shows the applied prestrain $\left(\varepsilon_{\mathrm{fp}, 0}\right)$ and the instantaneous losses $\left(\Delta \varepsilon_{\mathrm{fp}, \mathrm{i}}\right)$. A typical development of the strain with the time for slabs strengthened with the MA and GA systems can be observed in Figure 3 and Figure 4, respectively. In average the instantaneous prestress loss $(1.2 \mathrm{kN})$ corresponds to $2.7 \%$ of the total prestress force.

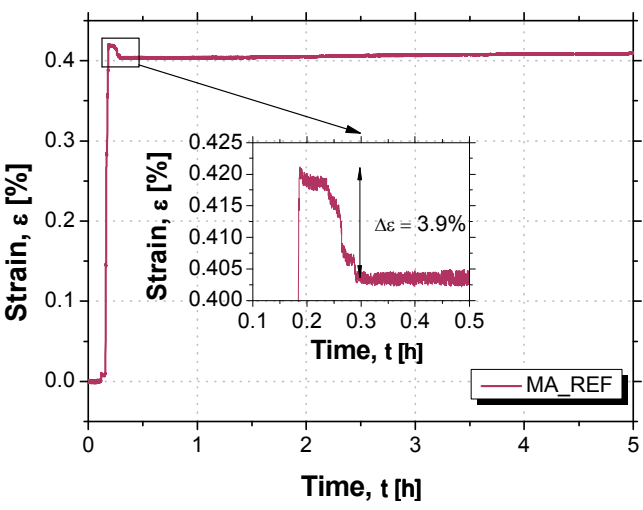

Figure 3. Typical short-term losses for $M A$ specimens (MA_REF)

Based on the monotonic tests of series TO, a

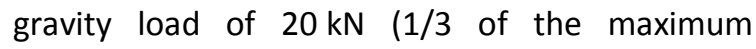
carrying capacity of the strengthened slabs) was used in the creep tests, as sustained load. During the placement of the load, a visual inspection and a continuous monitoring of the mid-span deflections allowed the identification of the crack initiation (for a load level in between $13.2 \mathrm{kN}$ and $17.5 \mathrm{kN}$ ).

The values of the elastic mid-span deformations $\left(\delta_{c, \text { ela }}\right)$, ultimate mid-span deformations $\left(\delta_{c, u l t}\right)$ and

creep coefficients $(\varphi)$ are presented in Table 2. In general, the observed elastic deformations (average $\delta_{c, \text { ela }}$ of $4.4 \mathrm{~mm}$ ) are with agreement with the results obtained in the monotonic tests of series TO.

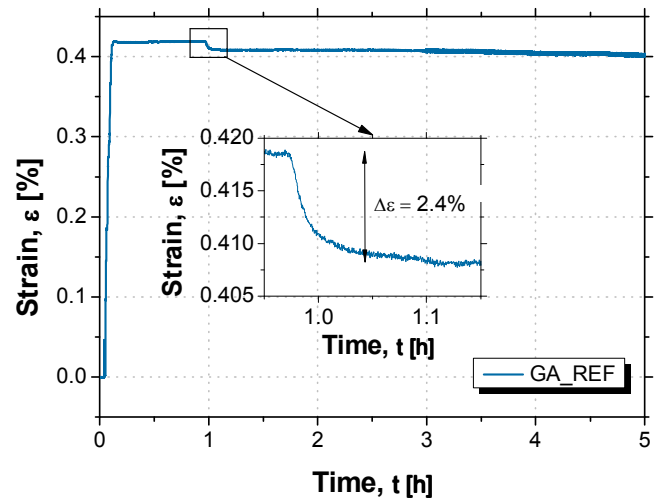

Figure 4. Typical short-term losses for GA specimens (GA_REF)

Both anchorage systems presented similar response during the creep tests. However, in the CW and WD environments, the specimens with the GA have shown larger deformations. This behaviour can be related to the lower mechanical properties of the epoxy adhesive at the anchorage zone of such system. Figure 5 shows the typical evolution of mid-span deformation during the creep tests and the recovery stage after unloading. As expected, the mid-span deformation increased at higher rates in the early days of the creep tests. Results showed that half of the maximum creep mid-span displacement was developed within the first 600 hours.

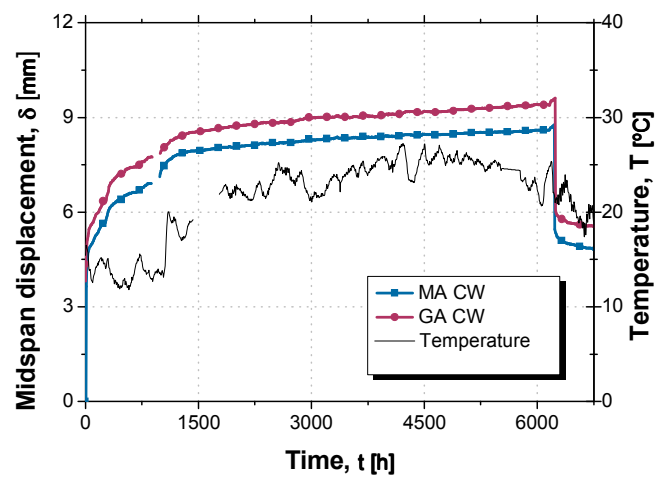

Figure 5. Evolution of mid-span displacement for specimens of series $\mathrm{CW}$ 
The creep coefficient $(\varphi)$ was defined as the ratio between the increment of creep mid-span displacement $\left(\delta_{c, \text { ult }}-\delta_{c, \text { ela }}\right)$ and the instantaneous elastic mid-span deformation $\left(\delta_{c, \text { ela }}\right)$. A maximum creep coefficient of 1.5 was observed in series TW and WD, for specimens with the gradient anchorage. Based on the studied period, a prediction of the creep coefficient for $t_{\infty}$ doesn't excess the value of 2.0 .

\subsection{Ultimate behaviour}

As mentioned before, monotonic tests up to failure were carried out. Specimens that belong to series TO were tested at the onset of this study. The remaining slabs (series REF, TW, CW and WD) were tested after the creep tests. As expected, the strengthened slabs with CFRP laminate significantly increased their stiffness and reduced the corresponding mid-span deflection for a specific load level. The load levels registered at crack initiation and steel yielding of prestressed slabs were greater than the ones observed for unprestressed specimens (see Table 2).

\subsubsection{Failure Modes}

Three different types of failure modes were observed: (i) specimen MA_TO failed by CFRP rupture in tension when their strain at the midspan attained at about 1.5\% (see Figure 6a); (ii) EBR_TO and all GA slabs presented strip debonding cohesive at the concrete (see Figure 6d); and (iii) in the remaining slabs (MA_REF, MA_TW, MA_CW and MA_WD) the maximum load was observed when the CFRP laminate was pull-out from the metallic plate anchorage (see Figure $6 \mathrm{~b}$ ). It should be mentioned that the REF_TO test was stopped once the mid-span deflection reached $100 \mathrm{~mm}$ due to the LVDT measurement range limitation. The failure mode would most likely be in this case concrete crushing on the top fibre at mid-span.

The EBR_TO and all slabs with gradient anchorages exhibit a brittle failure and, because the strip detachment developed rapidly and very sudden, it's not clear to state the exact failure mode. However, flexural cracks developed at the centre region could have led to a strip intermediate debonding and consequent detachment of the CFRP (see Figure 6c).
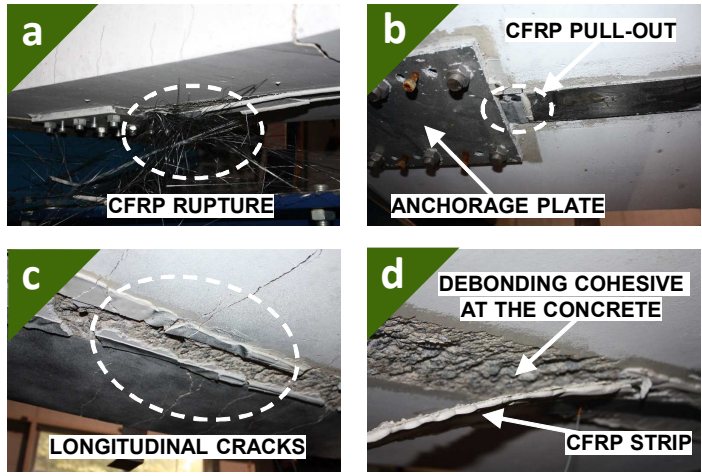

Figure 6. Failure modes: a) FRP rupture in unidirectional tension (MA_REF); b) CFRP strip pull-out from the mechanical end-anchorage (MA_WD); c) flexural cracks at the slab promoting the debonding (GA_TW); and d) detail of a cohesive at the concrete debonding (GA_WD).

All MA slabs presented a CFRP strip debonding inbetween anchorage plates. The metallic anchors of the MA system prevented a premature failure and enabled the slab to continue supporting load after that point: the MA_TO reached the CFRP maximum tensile capacity; whereas in the remaining MA slabs, the pull-out force from the metallic anchorage plate was decisive in the maximum carrying capacity of the slab.

\subsubsection{Anchorage Influence}

Both anchorage systems perform similarly until steel yielding. From this point on, the CFRP material is responsible to carry the additional loads since the contribution provided by the internal steel reinforcement is limited. For all MA specimens, the CFRP debonding initiation at both extremities (in between metallic plate anchors) was observed just after yielding initiation. Then, CFRP laminate strip behaved as an unbounded reinforcement held by the metallic anchors. On the other side, the CFRP debonding initiation in all GA slabs rapidly transformed in the complete detachment of the laminate and failure. For that reason the MA slabs presented a better performance in terms of ultimate load (6.2\%) and 
mid-span deformation (34.2\%) when compared in the GA specimens.

\subsubsection{Sustained load and environmental actions Influence}

During the creep tests eight slabs were subjected to the combined effect of four environments and a sustained load. These eight slabs performed similarly in the tests up to the failure, achieving similar ultimate load $(58.7 \mathrm{kN})$ and mid-span deformation $(46.7 \mathrm{~mm})$. When the slabs from series REF, TW, CW and WD are compared the slabs from series TO, the following observations could be noted: (i) decrease on the ultimate load of slabs subjected to creep tests ( $13.5 \%$ for series MA); and (ii) MA_TO failure was CFRP rupture, whereas all other MA slabs failed by CFRP slippage at the anchorage. Results show that the combined effect of the gravity load and environmental action produced higher degradation in slabs with MA than with GA. From all four environments, wet-dry cycling seamed to produce higher degradation on the ultimate load $(56.0 \mathrm{kN})$, at about $17 \%$. In the laboratory premises the MA_REF presented the highest ultimate load $(61.6 \mathrm{kN})$, mid-span displacement $(65.9 \mathrm{~mm})$ and CFRP strains $(0.13 \%)$ of all specimens subjected to the creep tests.

Table 2.Experimental program and main results

\begin{tabular}{|c|c|c|c|c|c|c|c|c|c|c|c|c|c|c|}
\hline \multirow[b]{2}{*}{ SPECIMEN } & \multirow[b]{2}{*}{ SERIES } & \multirow[b]{2}{*}{ ENVISONMENT } & \multicolumn{2}{|c|}{$\begin{array}{l}\text { Strain } \\
\text { Losses }\end{array}$} & \multicolumn{3}{|c|}{$\begin{array}{c}\text { Creep } \\
\text { Results }\end{array}$} & \multicolumn{2}{|c|}{$\begin{array}{c}\text { Crack } \\
\text { initiation }\end{array}$} & \multicolumn{2}{|c|}{ Yielding } & \multicolumn{3}{|c|}{ Ultimate } \\
\hline & & & $\begin{array}{c}\varepsilon_{\mathrm{fp}, 0} \\
{\left[10^{-3}\right]}\end{array}$ & $\begin{array}{c}\Delta \varepsilon_{\mathfrak{f p}, \mathrm{i}} \\
{[\%]}\end{array}$ & $\begin{array}{c}\delta_{c, \text { ela }} \\
{[\mathrm{mm}]}\end{array}$ & $\begin{array}{c}\delta_{c, \text { ult }} \\
{[\mathrm{mm}]}\end{array}$ & $\begin{array}{c}\varphi \\
{[-]}\end{array}$ & $\begin{array}{c}\delta_{\mathrm{cr}} \\
{[\mathrm{mm}]}\end{array}$ & $\begin{array}{c}\mathbf{F}_{\mathrm{cr}} \\
{[\mathrm{kN}]}\end{array}$ & $\begin{array}{c}\delta_{\mathrm{y}} \\
{[\mathrm{mm}]}\end{array}$ & $\begin{array}{c}F_{y} \\
{[k N]}\end{array}$ & $\begin{array}{c}\delta_{\max } \\
{[\mathrm{mm}]}\end{array}$ & $\begin{array}{l}F_{\max } \\
{[k N]}\end{array}$ & $\begin{array}{c}\varepsilon_{f, \max } \\
{\left[10^{-3}\right]}\end{array}$ \\
\hline REF_TO & \multirow{4}{*}{ T0 } & \multirow{4}{*}{$\begin{array}{l}\text { Tested at the } \\
\text { beginning of } \\
\text { the } \\
\text { experimental } \\
\text { program }\end{array}$} & -- & -- & -- & -- & -- & 0.7 & 7.9 & 18.9 & 24.5 & $100.0^{\mathrm{a}}$ & $28.1^{\mathrm{b}}$ & -- \\
\hline EBR_TO & & & -- & -- & -- & -- & -- & 0.9 & 8.5 & 25.9 & 37.1 & 40.7 & 44.0 & 0.8 \\
\hline MA_TO & & & 4.4 & 3.9 & -- & -- & -- & 1.8 & 17.9 & 26.9 & 50.6 & 84.8 & 67.5 & 1.5 \\
\hline GA_TO & & & 4.0 & 1.5 & -- & -- & -- & 1.6 & 16.2 & 29.0 & 50.2 & 43.3 & 57.4 & 1.2 \\
\hline MA_REF & \multirow{2}{*}{ REF } & \multirow{2}{*}{$\begin{array}{c}\text { Laboratory } \\
\text { premises, } 20^{\circ} \mathrm{C} \\
\text { and } 55 \% \mathrm{Rh}\end{array}$} & 4.1 & 3.9 & 4.8 & 11.2 & 1.3 & -- & -- & 26.2 & 48.1 & 65.9 & 61.6 & 1.3 \\
\hline GA_REF & & & 4.1 & 2.4 & 4.7 & $10.6^{c}$ & -- & -- & -- & -- & -- & -- & -- & -- \\
\hline MA_TW & \multirow{2}{*}{ TW } & \multirow{2}{*}{$\begin{array}{l}\text { Immersion in } \\
\text { water, } 20^{\circ} \mathrm{C}\end{array}$} & 4.0 & 3.0 & 4.8 & 9.9 & 1.0 & -- & -- & 22.0 & 50.5 & 41.3 & 57.7 & 1.2 \\
\hline GA_TW & & & 4.1 & 1.2 & 3.9 & 9.7 & 1.5 & -- & -- & 23.6 & 49.3 & 37.0 & 56.2 & 1.1 \\
\hline MA_CW & \multirow{2}{*}{$\mathrm{CW}$} & \multirow{2}{*}{$\begin{array}{l}\text { Immersion in } \\
\text { water with } \\
\text { chlorides, } 20^{\circ} \mathrm{C}\end{array}$} & 4.0 & 3.3 & 4.0 & 8.8 & 1.2 & -- & -- & 19.7 & 47.4 & 38.4 & 58.7 & 1.1 \\
\hline GA_CW & & & 4.1 & 2.4 & 4.3 & 9.3 & 1.2 & -- & -- & 21.9 & 47.0 & 39.0 & 57.0 & 1.1 \\
\hline MA_WD & \multirow{2}{*}{ WD } & \multirow{2}{*}{ Wet-dry cycles } & 4.0 & 3.5 & 4.1 & 9.9 & 1.4 & -- & -- & 20.1 & 48.6 & 32.9 & 55.6 & 1.0 \\
\hline GA_WD & & & 4.0 & 2.3 & 4.3 & 10.9 & 1.5 & -- & -- & 23.7 & 49.2 & 37.6 & 56.3 & 1.2 \\
\hline
\end{tabular}

Note: ${ }^{a}$ These slabs reached the maximum pre-defined deflection without failing; ${ }^{b}$ Values for the mid-span deflection of $100 \mathrm{~mm}$; Values for mid-span deflection at the age of 168 days (before failure).

\section{Conclusions}

This work presented an experimental program in which the main objective was to assess the short and long-term behaviour of RC slabs strengthened with prestressed CFRP laminate strips through two different anchorage systems: the mechanical anchorage (MA) and gradient anchorage (GA). The performed tests led to the following main conclusions: 
1. A similar response was observed for both anchorage techniques, yet the mechanical anchors of the MA system prevented a premature failure and allowed the slabs to support greater ultimate loads and deflections;

2. The MA_TO slab was the only that failed by FRP rupture at its maximum tensile capacity;

3. For the GA specimens, the initial debonding process was rapidly transformed into the complete strip detachment, resulting in a brittle failure;

4. The instantaneous losses of prestress measured were higher in the MA specimens. The average instantaneous losses correspond to $2.7 \%$ of the total prestress force initially applied.

5. In the creep tests, the observed elastic deformations are in agreement with the monotonic tests up to failure of series TO. A maximum creep coefficient of 1.5 was observed in series TW and WD and, based on the studied period. A prediction of the creep coefficient for $t_{\infty}$ doesn't excess the value of 2.0.

6. After being subjected to the creep test, a decrease on the ultimate load $13.5 \%$ for series MA) was observed. The failure mode of the MA slabs also changed from CFRP rupture (MA_TO) to CFRP slippage at the anchorage.

7. Wet-dry cycling seamed to produce higher degradation on the ultimate load $(56.0 \mathrm{kN})$, which corresponds a decrease at about $17 \%$ when compared series T0. The laboratory premises presented the highest ultimate load $(61.6 \mathrm{kN})$, mid-span displacement $(65.9 \mathrm{~mm})$ and CFRP strains $(0.13 \%)$ of all specimens subjected to the creep tests.

\section{Acknowledgements}

This work is supported by FEDER funds through the Operational Program for Competitiveness Factors - COMPETE and National Funds through FCT - Portuguese Foundation for Science and Technology under the projects FRPreDur - FCOMP-
01-0124-FEDER-028865

(PTDC/ECM-

EST/2424/2012) and FRPLongDur - POCI-01-0145FEDER-016900 (FCT PTDC/ECM-EST/1282/2014) and partly financed by the project POCI-01-0145FEDER-007633.

The authors thank all the companies that supported and contributed for the development of this study, mainly: S\&P Clever Reinforcement Ibérica, S\&P Clever Reinforcement Company (Switzerland), Tecnipor, Vialam, Hilti, Artcanter and Nova Europa. The second author also wishes to acknowledge the grant SFRH/BD/99309/2013 provided by FCT.

Finally, this paper is dedicated to Tiago Teixeira (1988-2015), former doctoral student at the ISISE R\&D Research Centre at the University of Minho and team member of the project FRPreDur.

\section{References}

[1] R. El-Hacha, R. Wight, and M. Green, "Prestressed fibre-reinforced polymer laminates for strengthening structures," Prog. Struct. Eng. Mater., vol. 3, no. 2, pp. 111-121, Apr. 2001.

[2] J. Michels, J. Sena-Cruz, C. Czaderski, and M. Motavalli, "Structural Strengthening with Prestressed CFRP Strips with Gradient Anchorage," J. Compos. Constr., vol. 17, no. 5, pp. 651-661, 2013.

[3] J. Michels, J. Sena-Cruz, R. Christen, C. Czaderski, and M. Motavalli, "Mechanical performance of cold-curing epoxy adhesives after different mixing and curing procedures," Compos. Part B Eng., vol. 98, pp. 434-443, 2016.

[4] L. Correia, T. Teixeira, J. Michels, J. A. P. P. Almeida, and J. Sena-Cruz, "Flexural behaviour of RC slabs strengthened with prestressed CFRP strips using different anchorage systems," Compos. Part B Eng., vol. 81, pp. 158-170, 2015. 